\title{
Reduction of accidents on public roads by increasing informativeness of drivers
}

\author{
Voevodin E. S. \\ Siberian federal university \\ associate Professor of the Department of Transport \\ Krasnoyarsk \\ ves_1981@mail.ru \\ Kashura A. S. \\ Siberian federal university \\ associate Professor of the Department of Transport \\ Krasnoyarsk \\ Fomin E. V. \\ Siberian federal university \\ senior lecturer of the Department of Transport \\ Krasnoyarsk
}

\begin{abstract}
The article reveals the cause of road accidents in the passing direction on the federal roads of the Krasnoyarsk Territory. Analysis of the composition of the traffic flow showed that $50 \%$ of cars in the Russian Federation are not equipped with the ABS system. Studies of the magnitude of the braking distance showed that when driving at low speeds up to $30 \mathrm{~km} / \mathrm{h}$ on surfaces with a high coefficient of adhesion, the effect of ABS is not significant. However, if the coupling properties of the tireroad deteriorate and the speed regime is increased, the effect of ABS is increased, while the reduction of the braking distance can reach $30 \%$. On the federal roads of the Krasnoyarsk Territory, the average speed is much more than $30 \mathrm{~km} / \mathrm{h}(93 \mathrm{~km} / \mathrm{h})$. Since the braking distance of cars equipped with $\mathrm{ABS}$ is much less than the braking distance of vehicles that are not equipped with a system, it is proposed to separate cars with electronic safety systems for braking and stabilizing traffic from the general flow. Allocation of cars equipped with ABS system will alert the driver of the vehicle that is driving the car with the ABS system about the need to maximize the distance and keep it constantly.
\end{abstract}

Keywords— intensity, safety, speed, distance, ABS.

\section{INTRODUCTION}

In the Krasnoyarsk Territory, collisions account for up to $40 \%$ (1506) of the total number of road accidents, in which up to $41 \%$ (165) die from the total number of deaths. Annually in the intercity network, up to $32 \%$ of the total number of accidents occurs; the proportion of deaths from the total number is $70 \%$. The main peak of an accident occurs during the summer period [1]. This is due to the climate, including transport from other regions [2]. Accidents happen because of unfavorable climatic conditions that reduce the coupling properties of tires with the road and impair visibility.

The largest number of deaths is in collisions $(62 \%$ of the total number of accidents) (Fig. 1). Collisions in the opposite

\author{
Pulyanova K.V. \\ Siberian federal university \\ Master's degree student \\ Krasnoyarsk
}

\author{
Askhabov A. M. \\ Siberian federal university \\ associate Professor of the Department of Transport \\ Krasnoyarsk \\ Golub N.V \\ Siberian federal university \\ senior lecturer of the Department of Transport \\ Krasnoyarsk
}

direction are spontaneous and occur on different sections of federal roads, as well as in places where it is possible to identify them in the analysis of traffic accident statistics.

Collisions are observed when the distance is not considered by the driver following in a passing direction, or when there is an abrupt stop in front of the moving vehicle. To reduce braking distances and to maintain the ability to control transport checks during braking, various brake systems are used.

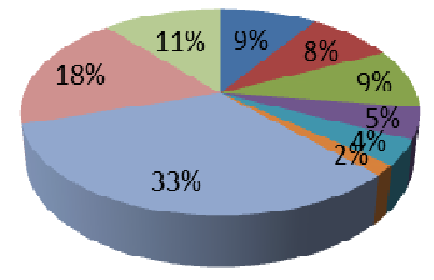

$\begin{array}{ll}\square \text { exit from the road } & \text { w overturning } \\ \square \text { hitting a pedestrian } & \square \text { running into a standing vehicle } \\ \square \text { hitting an obstacle } & \text { m another kind of accident } \\ \square \text { frontal collision } & \square \text { collision incident } \\ \square \text { collision cross } & \end{array}$

Fig. 1. Distribution of deaths by types of road accidents on the federal roads of the Krasnoyarsk Territory

Along with the familiar ABS anti-lock system, DSC stability control system and ETS traction control system, there are:

- HDC (Hill Descent Control) — automatic deceleration system on descent; 
- EBD (Electronic Brake Distribution) - electronic distribution of braking forces along the axles of the car;

- CBC (Cornering Brake Control) — a system for distributing brake forces on the sides of the car during bends;

- EBA (Electronic Brake Assist) - system for emergency braking [4].

There are also systems of autonomous emergency braking. This system automatically works without any driver involvement, stopping the car in case of collision danger. Basically the system first warns the driver of the danger. If the driver does not respond to a warning, then an autonomous emergency braking will work $[5,6,7]$.

The principle of operation of these systems is diverse, as are their many names. On different machines there is a specificity of the work of such security systems. So on Volvo cars (City Safety system) and Ford (City Stop), stand-alone emergency braking operates at speeds up to $30 \mathrm{~km} / \mathrm{h}$, first warning the driver about the danger of collision and then if the driver does not react, the system automatically stops the car to prevent a collision. In Mercedes-Benz (Active Brake Assist) and Nissan / Infiniti (Intelligent Brake Assist) systems, automatic braking systems operate not only at low speeds, but are also capable of automatically stopping the car at high speed. Systems are able to determine the level of collision hazard [5].

At the moment, all cars that have been sold in Europe since 2004 are necessarily equipped with the anti-lock system. In Russia, this law came into force on January 1, 2016. Therefore, foreign cars bought earlier than 2004 and domestic cars - earlier than 2016 can be considered conditionally not equipped with an $\mathrm{ABS}$ system.

According to the Autostat on July 1, 2016 in the Russian Federation, Russian brands account for $41 \%$ of the fleet of cars, while the age of $91 \%$ of these cars exceeds 3 years. Also $32.7 \%$ of the total number of foreign cars $(59 \%)$ are older than 10 years [8]. Consequently, we can conditionally assume that $37 \%$ of the fleet of domestic cars and $18 \%$ of foreign cars are not equipped with $\mathrm{ABS}$.

\section{FORMULATION OF THE PROBLEM}

The purpose of the work is to investigate the process of braking cars, equipped and not equipped with $\mathrm{ABS}$, under various road conditions.

\section{THE SOLUTION OF THE PROBLEM}

According to the purpose, in our experiment, the controlled factor is the speed of the car before the braking begins, and the remaining parameters are output and will be fixed after the fact. In preliminary experiments, we determined that:

- variations in vehicle speed from $\min$ to $\max$ are possible in the range from 5 to $110 \mathrm{~km} / \mathrm{h}$ (below $5 \mathrm{~km} /$ $\mathrm{h}$, ABS does not work, and above $110 \mathrm{~km} / \mathrm{h} \mathrm{-} \mathrm{the}$ maximum permitted speed in a given area);
- the operator needs to make braking gradually increasing the initial speed by $5 \mathrm{~km} / \mathrm{h}$, which will allow obtaining a high degree of reliability at all possible speed intervals.

Controlled parameters and ranges of their variation are summarized in Table I.

TABLE I. CONTROLLED PARAMETERS AND THEIR RANGES

\begin{tabular}{|c|c|}
\hline Controlled parameter & Variation range \\
\hline Initial speed of braking, $\mathrm{km} / \mathrm{h}$ & $5-110$ \\
\hline The force of pressing the pedal, $\mathrm{N} * \mathrm{~m}$ & $1-200$ \\
\hline Acceleration (deceleration), $\mathrm{m} / \mathrm{s}^{2}$ & $0-10$ \\
\hline Braking distance, $\mathrm{m}$ & $0-100$ \\
\hline Deceleration time, $\mathrm{s}$ & $0-10$ \\
\hline
\end{tabular}

The experiment will require a set of Corrsys-Datron equipment, as well as a Volkswagen Transporter $7 \mathrm{HC}$ vehicle itself. The end result will be the dependence of the braking distance on the speed of the vehicle with ABS on/off.

For the collection and recording of data, the CorrsysDatron measuring complex was used, providing the ability to unfold and record the following signals in time and fixation: $\mathrm{N}$ (t) - brake pedal force; $v(t)$ - the speed of automatic telephone exchange; $\mathrm{S}(\mathrm{t})$ is the passed way of the automatic telephone exchange during the deceleration time; a $(\mathrm{t})$ is the current deceleration of the automatic telephone exchange. The measuring system consists of the following instruments and sensors:

- DAS-3 - data acquisition and processing system for measuring the full dynamics of the movement of automatic telephone exchanges by CORREVIT sensors. A CompactFlash card is used to record and then take down information.

- Non-contact single-axis optical sensor for measuring the longitudinal dynamics of CORREVIT L-350 Aqua.

- Sensor for measuring force on the controls of Corrsys Datron. It allows determining the force of pressing the brake pedal control during brake tests by means of a digital indicator and outputting a signal for recording in DAS-3 the data on the force of pressing the brake pedal.

\section{- Software CeCalWin CORRSYS-DATRON.}

The tests were carried out on a Volkswagen 7HC Transporter. At the time of testing, the mileage of the car was 6 thousand $\mathrm{km}$, therefore, the brake mechanisms were run-in and their wear was insignificant. The rate of depression of the brake pedal was conventionally divided into three groups: fast - time the rise in the force to a peak value of less than 1.5 seconds, the average from $1.5 \mathrm{sec}$. up to $3 \mathrm{sec}$. and slow more than 3 seconds.

Test conditions: dry asphalt-concrete coating; the initial speed of braking is from 5 to $110 \mathrm{~km} / \mathrm{h}$; braking with the engine disconnected (with the clutch depressed). The tests were carried out both with working ABS and with ABS off. 
To remove data from the DAS-3 data acquisition and processing unit, a personal computer with the pre-installed software CeCalWin CORRSYS-DATRON was used. According to the data obtained, the braking process was plotted in Microsoft Excel [8].

The results of the experiment will be summarized in a protocol (in a Microsoft Excel file), which is a set of numbers (current values of the signals of the measured parameters with the specified period of the sensors interrogation $0.01 \mathrm{sec}$ ), the processing of which is very difficult.

Therefore, the purpose of the primary processing of the experimental results is to bring them into a form more suitable for further analysis. To do this, using the "Chart Wizard" from Microsoft Excel, based on the results of each measurement, we plot the graphs (Fig. 2) of the physical quantities under study, then determine the parameters of interest to us by these graphs:

- brake pedal force,

- deceleration time $\mathrm{t}$,

- stopping distance $S$,

- initial speed of braking,

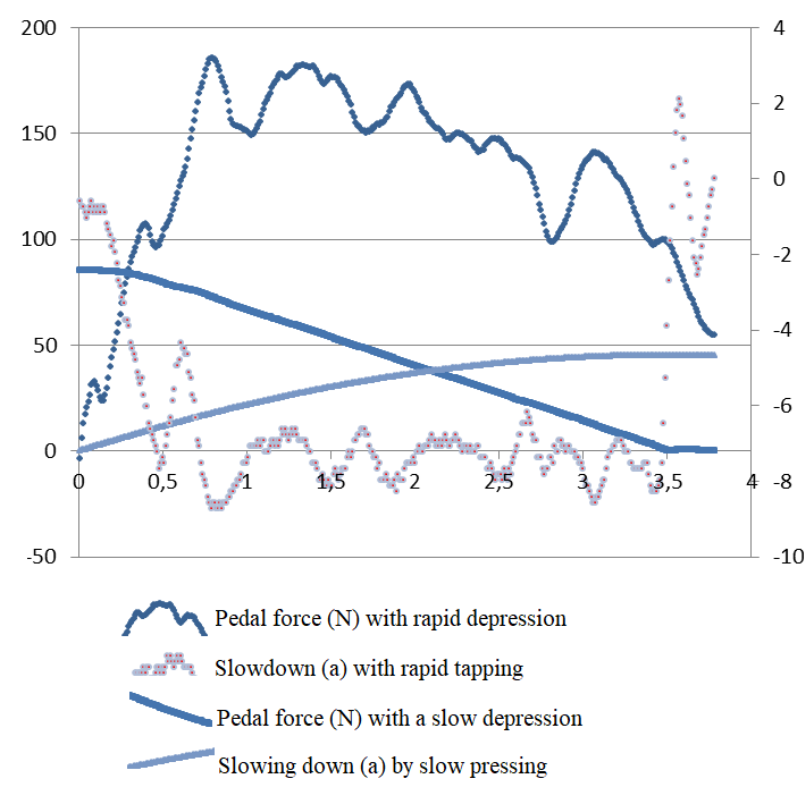

Fig. 2. Graphical representation of measured procedural parameters

To carry out statistical models, we perform a correlationregression analysis of experimental data and construct models linking the magnitude of the stopping distance from the speed of the car.

We will analyze the parameters of this model using different models. As an independent variable, we will consistently take procedural parameters (Fig. 3 and Fig. 4).

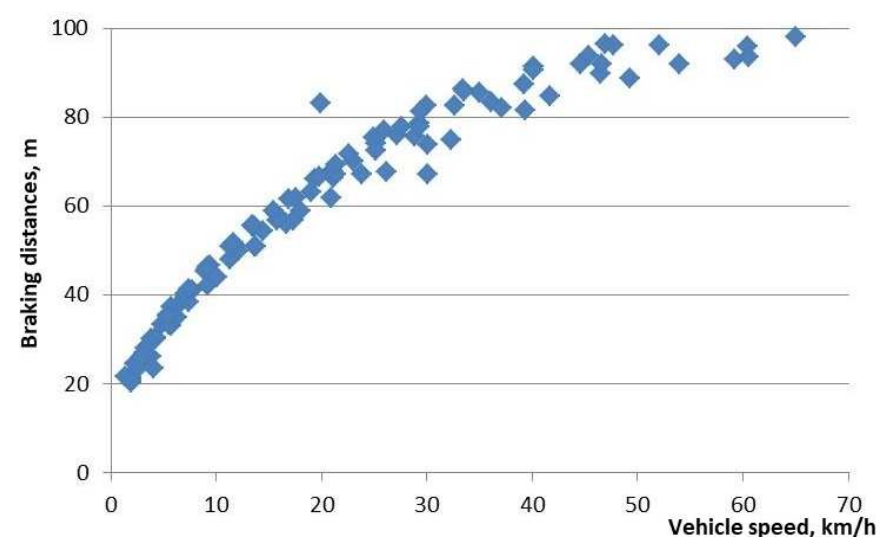

Fig.3. Dependence of the braking distance on the speed of the car with $\mathrm{ABS}$ off, the number of races 110 .

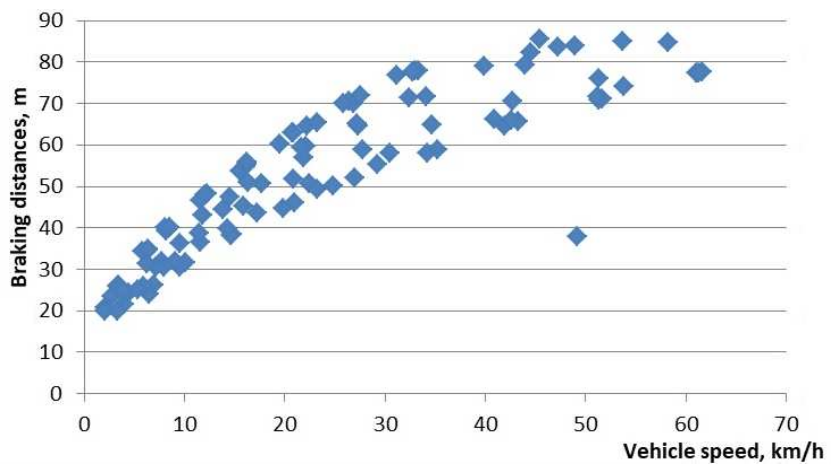

Fig. 4. Dependence of the stopping distance on the speed of the car with ABS on, the number of races 110 .

The analysis of the obtained data allows us to recommend for further use an adaptive model of the following type:

$$
\mathrm{S}=\mathrm{aV}^{2} \text {. }
$$

This model contains a parameter that, as shown by the analysis of the results, is individual for each car and will depend on many factors (technical condition of the vehicle, road conditions, fuel quality, weather conditions, etc.), and on the availability and serviceability of electronic systems, providing effective braking.

In addition, the equipment used in the studies did not take into account the reaction time of the driver in an emergency situation. From the literature sources it is known that this parameter varies in the range from 0.5 to 2.0 seconds and mainly depends on the physiological characteristics of the subject [9-11]. Therefore, the final model takes the form:

$$
\mathrm{S}=\mathrm{V} \cdot \mathrm{t}_{\mathrm{pv}}+\mathrm{aV}^{2}
$$

where $\mathrm{V}$ - initial speed of braking, $\mathrm{m} / \mathrm{s} ; \mathrm{t}_{\mathrm{pv}}$ - driver reaction time, s; a - coefficient that takes into account the technical condition of the car;

For a car with $\mathrm{ABS}$ running, the coefficient is $\mathrm{a}=0.0045$; with ABS off or on, $\mathrm{a}=0.006$ [12-14].

Let us present the results of modeling on the final graph (Fig. 5) 


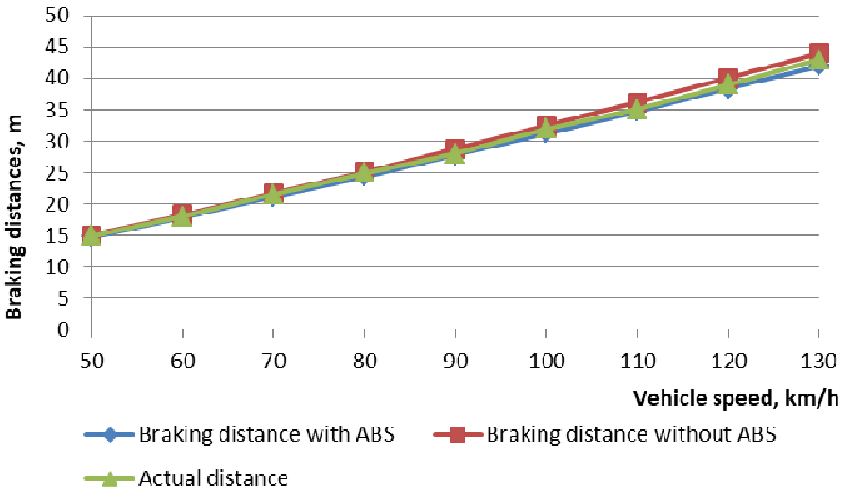

Fig. 5. Graphical representation of simulation results

As a result of the simulation, it can be seen that if a car equipped with $\mathrm{ABS}$ system is followed by a car not equipped with the ABS system, its braking distance will not be sufficient for emergency braking.

We carried out an analogy between the braking path of cars equipped and not equipped with $\mathrm{ABS}$ and cars on studded tires and friction rubber. The results of this comparison are shown in Figure 6. As a result of the comparison, it can be concluded that when driving at low speeds up to $30 \mathrm{~km} / \mathrm{h}$ on surfaces with a high coefficient of adhesion, the effect of ABS is not significant. However, with deterioration of the coupling properties of the tire-road and an increase in the speed regime, the influence of the ABS increases, while a decrease in the braking distance can reach $30 \%$.

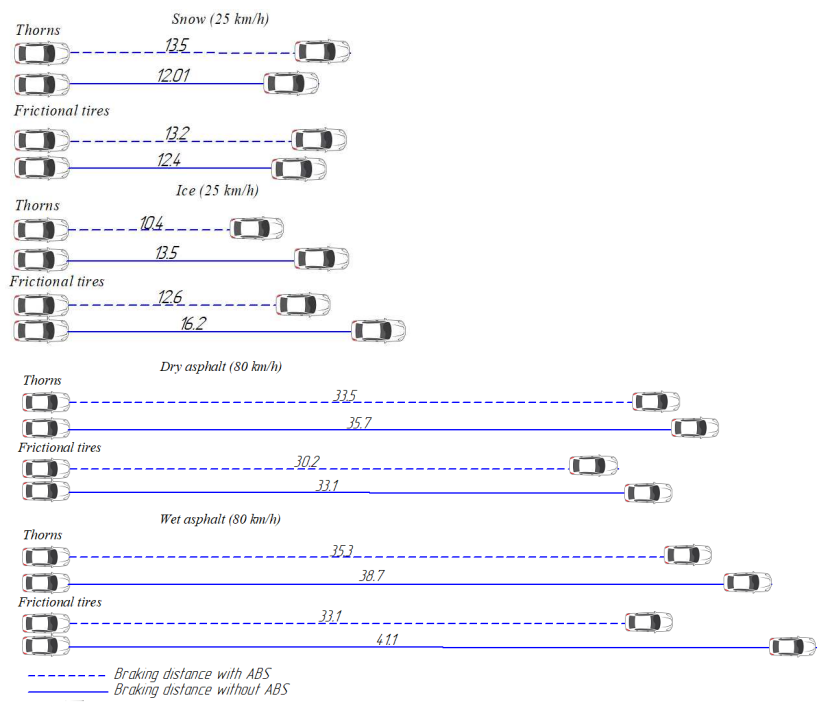

Fig. 6. Braking with ABS on different road surfaces

Due to the climatic features and slippery roads in winter, it was decided at the legislative level to allocate cars equipped with studded tires. On such cars the "Spikes" sign should be installed. Its main purpose is to notify other road users about the presence of studded tires from the car driving in front. By installing this sign, the driver warns that his car is on studded tires, and therefore:

a) the braking distance of the car on a slippery surface is much less than that of others; b) spikes may fly out from under the wheels.

According to traffic rules, the driver of a vehicle that is driving a car with studded tires and sees confirmation of this in the form of a sign "Thorns" and is obliged to maximize the distance and keep it constantly. Then, in case of sudden braking, it will not crash in front of the driving car, which, due to the spikes, can stop very abruptly.

Since the braking distance of cars equipped with the ABS system is much less than the braking distance of vehicles not equipped with the system, and such cars account for up to $50 \%$ of the car fleet, there is a need to separate these cars from the common traffic flow. Allocation of cars equipped with ABS system will alert the driver of the vehicle who is driving the car with the ABS system about the need to maximize the distance and keep it constantly. Then, in case of sudden braking, he will not allow a collision with the car in front.

For the allocation of cars with electronic safety systems during braking and stabilization of traffic from the general transport stream, it is suggested to use the following sign (Fig.7).

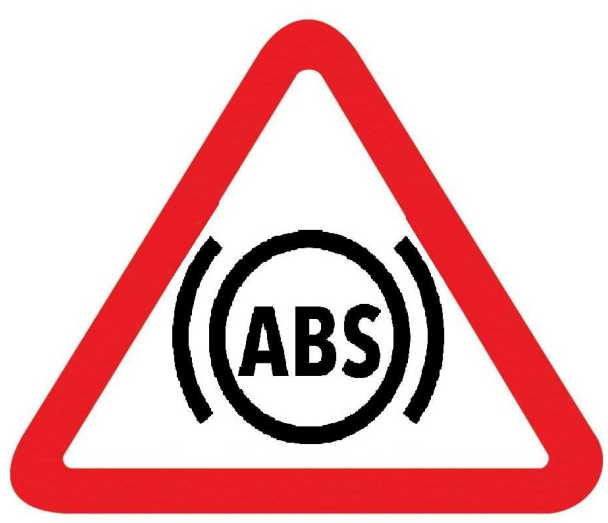

Fig.7. Suggested ABS sign

\section{CONCLUSION}

Increasing the information content of drivers on public roads by designating vehicles equipped with the ABS system and other similar systems will allow reducing the number of road accidents in the form of a collision in the passing direction (today it is 18\%) and the severity of their consequences.

\section{References}

[1] SRSI, Information on indicators of the state of road safety. Retrieved from: http://www.gibdd.ru;

[2] Federal Road Agency Rosavtodor FKU "Baikalupravor", Federal highways. Retrieved from: http://www.fuadbaikal.ru/index.php/federalnye-avtodorogi/set-dorog/obshchaya-skhemaRoads

[3] Weather Diary. Weather Diary in Krasnoyarsk. Retrieved from: https://www.gismeteo.ru/diary/4674/2016/7/;

[4] R.F. Zarulem, Perspective directions of braking systems development. Retrieved from: http://wiki.zr.ru/Perspective_regions_development_of braking systems

[5] 1gai.ru, Modern brake systems in cars. Retrieved from: http://www.1 gai.ru/publ/512967-sovremennye-tormoznye-sistemy-vavtomobilyah.html; 
[6] Yuan-Lin Chen "Investigation of a new probability index of the collision probability of a straight line," Int. J. Safety Safety, Vol. 8, No. 3, pp. 193-204, 2015. DOI: 10.1504 / IJVS.2015.070762

[7] V.V. Elistratov, S.I. Bezrukov, P.G. Stenin, V.S. Klimakov "The concept of development of collision safety systems for vehicles," Scientific Review. Technical science, No. 1, pp. 178-178, 2015.

[8] Analytical agency AUTOSTAT. Infographics. Retrieved from: https://www.autostat.ru/infographics/27063/

[9] V.I. Grachev, I.M. Blyankinstein, E.S. Voevodin, A.S. Kashura, On the influence of subjective qualities of the tester on the braking dynamics of automatic telephone exchanges. Youth and Science: A Compendium of Materials of the VIII All-Russian Scientific and Technical Conference of Students, Graduate Students and Young Scientists, dedicated to the 155th anniversary of the birth of KE Tsiolkovsky, Krasnoyarsk: Siberian Federal University, 2012.
[10] D. Ljubenov "Research of a stop of various road conditions," Transport problems, vol. 6, № 4, pp. 119-126, 2011.

[11] A.S. Terekhov, V.A. Tyulkin, I.M. Titla, I.I. Kucherenko "Influence of the driver's age on the response time to a moving object," Scientific and Technical Herald of the Volga Region, № 2, pp. 186-189, 2015.

[12] R.V. Zabolotniy "Towards a definition of the time and path of friction of brake mechanisms and tires of cars with ABS," Izvestia Volgograd State Technical University. Series: Surface transport systems, vol. 2. No. 8 (34), pp. 121-122, 2007.

[13] A. Akhmetshin, V.A. Ryazantsev "Studies of the process of braking the car with ABS," Journal of Automotive Engineers, No. 1 (90), pp. 16-19, 2015 .

[14] Lin Li, Xishan Zhu, Ma. ZhiSiong "Behavior of the driver during braking in scenarios close to an accident," International Journal of Vehicle Safety, Vol. 7 (3/4), pp. 374 - 389, 2014. DOI: 10.1504 / IJVS.2014.063249 